\title{
ANAEMIA IN 6 - 59 MONTHS CHILDREN IN RURAL KERALA AND ITS ASSOCIATION WITH AGE, GENDER, NUTRITIONAL STATUS AND DIETARY HABITS
}

\author{
Shyama Manoj', Isac Mathai Meppadath² \\ 1 Postgraduate Student, Department of Paediatrics, MOSC Medical College, Kolenchery. \\ 2 Professor and HOD, Department of Paediatrics, MOSC Medical College, Kolenchery.
}

ABSTRACT
BACKGROUND
Anaemia is a condition that is widely prevalent among all age groups, highest being around $80 \%$ children under 3 years of age.
Present study was to determine the prevalence of anaemia in children in $6-59$ months old, admitted in the paediatric ward and to
evaluate its association with age, gender, nutritional status and dietary habits.

\section{MATERIALS AND METHODS}

The study was conducted in 500 children admitted to the paediatric ward in MOSC Medical College, Kolenchery for a period of 1 year. Study was restricted to the children of age between 6 - 59 months. Haemoglobin and red cell indices of blood samples were estimated using automatic analyser. The check list included basic details like age, gender, weight, height, food habits. In infants and toddlers, the pattern of breast feeding and duration was also included.

\section{RESULTS}

The prevalence of anaemia among children of 6 - 59 months old was $25.8 \%$. Prevalence was highest in children aged 6 - 11 months and lowest in 36 - 59 months. The prevalence among males and females is $32.5 \%$ and $17.3 \%$, respectively; $13 \%$ of the sample was undernourished and of which $41.53 \%$ had anaemia. Anaemia was seen among overweight children also. Food habits showed significant association with anaemia.

\section{CONCLUSION}

Globally, policy makers have deployed strategies against anaemia which include iron supplementation, food fortification, deworming, dietary diversification. Despite this, anaemia prevalence is high and possible reasons are suboptimal program implementation, lack of adherence or other unidentified causes. Thus, additional work is required to identify the reason for the gap between policy and practices for anaemia control in this setting.

\section{KEYWORDS}

Anaemia, Nutritional Status, Dietary Habit.

HOW TO CITE THIS ARTICLE: Manoj S, Meppadath IM. Anaemia in 6 - 59 months children in rural Kerala and its association with age, gender, nutritional status and dietary habits. J. Evolution Med. Dent. Sci. 2017;6(29):2358-2361, DOI: $10.14260 /$ Jemds/2017/508

\section{BACKGROUND}

Anaemia is a condition in which the number of red blood cells or their oxygen-carrying capacity is insufficient to meet physiologic needs which vary by age, sex, altitude, smoking and pregnancy status. Most anaemia develops gradually and progressively. The effects of anaemia on children are direct as their body is developing including the brain, which is the fastest developing organ in infancy and early childhood. Anaemia leads to impaired cognitive function, growth and psychomotor development. The most common reason for anaemia in infants and children is nutritional anaemia due to inadequate supply of iron, folic acid and vitamin $\mathrm{B}_{12}$. In early childhood, faulty feeding practices especially during weaning period exacerbate the problem.

Financial or Other, Competing Interest: None.

Submission 04-03-2017, Peer Review 27-03-2017,

Acceptance 03-04-2017, Published 10-04-2017.

Corresponding Author:

Dr. Isac Mathai Meppadath,

Professor and HOD,

Department of Paediatrics,

MOSC Medical College,

Kolenchery.

E-mail: drisacmathai2016@gmail.com

DOI: $10.14260 /$ jemds $/ 2017 / 508$
Children go through periods of rapid growth and the diet should supply enough nutrients to facilitate the increased need. At its special session on children in 2003, the United Nations General Assembly set a goal to reduce the prevalence of anaemia by $1 / 3^{\text {rd }}$ by 2010 . Despite this during 1990 - 2010 periods, the incidence of anaemia in children aged less than 5 years has increased drastically. The World Health Organisation (WHO) has estimated that globally anaemia affects 1.62 billion people $(24.8 \%$ of the population). ${ }^{1}$ The highest prevalence of anaemia is among preschool aged children (47.4\%); of these 293 million children, 89 million live in India. The National Family Health Survey - 3 (NFHS-3) data suggests that anaemia is widely prevalent among all age groups, highest being around $80 \%$ children under 3 years of age (69.5\% in 6 - 59 months). In Kerala, $44.5 \%$ of under-five population is anaemic. ${ }^{2}$

\section{MATERIALS AND METHODS Study Population}

This is a cross-sectional study conducted in a private teaching hospital for a period of 1 year. Children aged between 6 - 59 months admitted in the hospital were included in the study. Those children requiring frequent blood transfusion, children with malignancy, severely sick patients, bleeding disorder, history of surgery within last 2 
months were excluded from the study. A total of 500 children were selected and screened for the study. The parent/care taker of the child was well informed about the study and written, informed consent was taken from them prior to sampling. Ethical approval for the study was taken from our Institutional Review Board. Information regarding age, sex, weight, dietary habits, birth weight, breast feeding practices including duration, type of complementary food in the $1^{\text {st }}$ year of life, current diet of the child, whether the child takes non-veg food, cereals, vegetables and fruits. History of blood transfusion or being treated for anaemia, history of being treated for helminthiasis, mother's education was collected and entered in the format.

Nutritional status was assessed through weight for age using an Electronic Weighing Scale. WHO growth charts were used to determine the nutritional status as normal nutrition, underweight or overweight. Data was plotted in separate growth charts for girls and boys. Dietary habits were classified broadly into vegetarians and non-vegetarians. Also, the intake of food items providing heme and non-heme iron. The data was compiled per age group, gender, nutritional status (weight for age) and dietary habits.

\section{Laboratory Analysis}

Laboratory investigations were done as per the recommended standard operating procedure; $2 \mathrm{~mL}$ venous blood was obtained in sterile blood collection tube with anticoagulant EDTA (Ethylene diamine tetra acetate). Complete haemogram was obtained using ADVIA 2120 Automatic haematology analyser. Those samples with $\mathrm{Hb}<$ $11 \mathrm{mg} \mathrm{dL}-1$ were analysed using automatic analyser. Complete blood count which includes red blood cell count, white blood cell count, platelet count and red cell indices, i.e. MCV, MCH, MCHC and RDW was obtained. Peripheral smear was screened for abnormal cells using microscope. Morphology of red cells was recorded by interpreting the red cell indices. The results were recorded in the data sheet. Severity of anaemia was classified based on WHO classification of anaemia. Mild $10-10.9 \mathrm{mg} \mathrm{dL}^{-1}$, moderate 7 $9.9 \mathrm{mg} \mathrm{dL}^{-1}$, severe $<7 \mathrm{mg} \mathrm{dL}^{-1}$.

\section{Statistical Analysis}

Data were entered using Microsoft Excel 2007, and analysed using SPSS. Data were summarised in frequency tables, pie chart and histogram. Continuous data were described as means (standard deviation) depending on the distribution of data. Statistical analyses were carried out using t-test, ANOVA and Pearson Coefficient Correlation. The 95\% confidence interval was determined and risk factors with $\mathrm{p}$ value of $<0.05$ were considered significant.

\section{RESULTS}

The demographic profile of the studied cases is depicted in Table 1. Table 2 and 3 describes the nutritional status and dietary habits of anaemic cases. Social status of mothers of studied children is depicted in Table 4. Classification according to severity of anaemia is shown in Table 5. In the case of nutritional status, about $23.41 \%$ anaemic children belong to normal category and $41.53 \%$ of anaemic cases belong to underweight category; $25.00 \%$ cases belong to overweight category. Statistical studies showed that there was significant difference ( $p$ value $=0.016$ ) between haemoglobin level with underweight. When classified according to severity of anaemia, $75.19 \%$ cases belonged to mild classification and $24.81 \%$ were classified as moderate category. None of the samples were documented under severe category.

\begin{tabular}{|c|c|c|c|}
\hline Variables & Total No. & Anaemic & Percentage \\
\hline Study Population & 500 & 129 & $25.80 \%$ \\
\hline \multicolumn{4}{|c|}{ Gender } \\
\hline Male & 280 & 91 & $32.50 \%$ \\
\hline Female & 220 & 38 & $17.27 \%$ \\
\hline \multicolumn{4}{|c|}{ Age } \\
\hline 06 - 11 Months & 120 & 55 & $45.83 \%$ \\
\hline 12 - 23 Months & 106 & 45 & $42.45 \%$ \\
\hline 24 - 35 Months & 91 & 18 & $19.78 \%$ \\
\hline 36 - 59 Months & 183 & 11 & $6.01 \%$ \\
\hline \multicolumn{2}{|c|}{ Table 1. Demographic Profile of the Studied Cases } \\
\hline
\end{tabular}

\begin{tabular}{|c|c|c|c|}
\hline Variables & Total No. & Anaemic & Percentage \\
\hline \multicolumn{4}{|c|}{ Nutritional Status } \\
\hline Normal & $427(85.4 \%)$ & 100 & $23.41 \%$ \\
\hline Underweight & $65(13 \%)$ & 27 & $41.53 \%$ \\
\hline Overweight & $8(1.6 \%)$ & 2 & $25.00 \%$ \\
\hline \multicolumn{4}{|c|}{ Birth Weight Age Group 06 to 11 Months, Total No. 120} \\
\hline$<2.5 \mathrm{~kg}$ & 26 & 9 & $34.62 \%$ \\
\hline$>2.5 \mathrm{~kg}$ & 94 & 46 & $48.9 \%$ \\
\hline
\end{tabular}

\begin{tabular}{|c|c|c|c|c|}
\hline Variables & & Total & Anaemic & Percentage \\
\hline \multirow{2}{*}{ Antenatal Iron and Folic Acid Tablets } & Taken & 116 & 53 & $45.69 \%$ \\
\hline & Not Taken & 4 & 2 & $50.00 \%$ \\
\hline \multirow{2}{*}{$\begin{array}{c}\text { Prolonged Exclusive Breast Feeding and delayed } \\
\text { introduction of Complementary Feed }\end{array}$} & Yes & 109 & 53 & $48.62 \%$ \\
\hline & No & 11 & 2 & $18.18 \%$ \\
\hline \multirow{2}{*}{ Formula Feeds } & Taken & 34 & 9 & $26.47 \%$ \\
\hline & Not Taken & 86 & 46 & $53.49 \%$ \\
\hline \multicolumn{5}{|c|}{ Age Group 12 to 23 Months, Total No. 106} \\
\hline \multirow[t]{2}{*}{ Predominantly breast fed } & Yes & 84 & 32 & $38.10 \%$ \\
\hline & No & 22 & 13 & $59.09 \%$ \\
\hline \multirow{2}{*}{ Milk and Milk Products } & Yes & 44 & 21 & $47.72 \%$ \\
\hline & No & 62 & 24 & $38.71 \%$ \\
\hline
\end{tabular}




\begin{tabular}{|c|c|c|c|c|}
\hline \multicolumn{5}{|c|}{ Age Group 06 to 59 Months, Total No. 500} \\
\hline \multirow{2}{*}{ Intake of cereals/pulses/tubers/vegetables } & Regular & 353 & 57 & $16.1 \%$ \\
\hline & Occasional & 147 & 66 & $44.89 \%$ \\
\hline \multirow{2}{*}{ Intake of fruits } & Regular & 331 & 59 & $17.82 \%$ \\
\hline & Occasional & 169 & 53 & $31.36 \%$ \\
\hline \multirow{2}{*}{ Diet } & Vegetarians & 140 & 61 & $43.57 \%$ \\
\hline & Non-Veg & 360 & 68 & $18.89 \%$ \\
\hline \multicolumn{5}{|c|}{ Non-Vegetarian Group, Total No. 360} \\
\hline \multirow{2}{*}{ Intake of fish/meant/poultry/egg } & Regular & 171 & 12 & $7.02 \%$ \\
\hline & Occasional & 189 & 56 & $29.63 \%$ \\
\hline \multicolumn{5}{|c|}{ Table 3. Dietary Habits of the Studied Cases, Age Group 06 to 11 Months, Total No. 120} \\
\hline
\end{tabular}

\begin{tabular}{|c|c|c|c|}
\hline Variables & Total No. & Anaemic & Percentage \\
\hline \multicolumn{4}{|c|}{ Education } \\
\hline School Level & 130 & 25 & $19.23 \%$ \\
\hline Graduate & 312 & 95 & $30.45 \%$ \\
\hline $\begin{array}{c}\text { Post Graduate/ } \\
\text { Professional }\end{array}$ & 58 & 8 & $13.79 \%$ \\
\hline \multicolumn{4}{|c|}{ Occupation } \\
\hline Homemaker & 158 & 46 & $29.11 \%$ \\
\hline Employed & 342 & 83 & $24.26 \%$ \\
\hline $\begin{array}{c}\text { Table 4. Social Status of Mothers of } \\
\text { the Studied Cases, Total No. 500 }\end{array}$ \\
\hline
\end{tabular}

\begin{tabular}{|c|c|c|c|c|c|}
\hline $\begin{array}{c}\text { WHO } \\
\text { Grading of } \\
\text { Anaemia }\end{array}$ & $\begin{array}{c}\text { Level } \\
\text { of Hb }\end{array}$ & Male & Female & Total & Percentage \\
\hline Mild & $\begin{array}{c}10-10.9 \mathrm{mg} \\
\mathrm{dL}^{-1}\end{array}$ & 67 & 30 & 97 & $75.19 \%$ \\
\hline Moderate & $\begin{array}{c}9.9-7.0 \mathrm{mg} \\
\mathrm{dL}^{-1}\end{array}$ & 24 & 8 & 32 & $24.81 \%$ \\
\hline Severe & $<7 \mathrm{mg} \mathrm{dL}^{-1}$ & - & - & - & 0 \\
\hline Total & & 91 & 38 & 129 & $100 \%$ \\
\hline Table 5. Classification according to Severity of Anaemia \\
\hline
\end{tabular}

\section{DISCUSSION}

Among 500 children recruited for the study, the prevalence of anaemia was $25.8 \%$. Studies conducted by Sales et al reported a prevalence of $36.3 \%^{3}$ and Dos Santos et al had prevalence of $56.6 \%$ of anaemia among under 5 children. ${ }^{4}$ In a study from Kerala by George et al showed $11.40 \%$ prevalence of anaemia among under 5 children. ${ }^{5}$

The study also evaluated that the male children are more affected $(32.5 \%)$ than females $(17.3 \%)$. P value of 0.012 showed that the results are statistically significant. More prevalence of anaemia in boys may be due to the faster growth of preschool boys compared to girls, which results in a higher iron demand that cannot be met by diet alone. In a study by George et al, the percentage of anaemic children among male and female children was $10.25 \%$ and $12.55 \%$ respectively and statistical analysis showed that female children were more susceptible to anaemia, 5 which is contradictory to the present study. The most affected age group is infants (45.8\%) and the least affected is between age group of 36 - 60 months (6.01\%). This observation was similar to the studies like Osorio et al. ${ }^{6}$

In our study population, the proportion of undernutrition is $(13 \%)$ and obesity is $(1.6 \%)$. Anaemia was found among overweight children also. Lack of vitamins and minerals was commonly observed in both conditions. The diet of obese or overweight children may be often characterised by excessive calories and insufficient intake of vitamins and minerals. NFHS-3 shows that almost half of the children under 5 years of age, $48 \%$ were stunted and $43 \%$ were underweight. ${ }^{2}$ Overall girls and boys are about equally undernourished. In George et al, normal nutritional status was seen among $46.7 \%$ of the children. ${ }^{5}$ When $187(11.78 \%)$ of the mild undernourished children were anaemic, the percentage among the moderate undernourished children was $16.37 \%$. Moderate undernutrition and anaemia showed a significant association. Osorio et al also found a higher prevalence of anaemia in malnourished children aged between 6 - 59 months. ${ }^{6}$ Aswathi et al also showed that in underweight children the mean haemoglobin level was $9.85 \pm 1.67$ as compared to $10.39 \pm 1.62$ in those without malnutrition $(\mathrm{p}<$ $0.0001) \cdot{ }^{7}$

Food habits showed significant association with anaemia ( $\mathrm{p}$ value $=0.03$ ). Anaemia was more among those who did not regularly take fish/meat (29.6\%), compared to those who regularly take (7\%). Anaemia was $44.89 \%$ in those who did not take cereals, tubers when compared to $16.1 \%$ who regularly take and was $31.36 \%$ in those who did not take fruits compared to $17.82 \%$ in those who regularly take. In George et al, anaemia was reported among both vegetarians and non-vegetarians. In their study among 927 vegetarians, $86(9.27 \%)$ were anaemic and among 2706 non-vegetarians $328(12.1 \%)$ were anaemic. 5

Children of 6 - 11 months' age group were studied separately. No significant association between birth weight and anaemia ( $\mathrm{p}$ value - .0145. Anaemia after 6 months is not associated with iron stores at birth. No significant correlation between antenatal iron and folic acid supplementation and anaemia after six months of age. Prolonged exclusive breast feeding with delay in introduction of complementary feeds is associated with anaemia ( $p$ value - 0.001). Sultan et al showed late weaning as a risk factor for anaemia among infants. Those taking formula feeds have less of anaemia ( $p$ value - 0.006). Iron content of breast milk and cow's milk is approximately 1 $\mathrm{mg} /$ litre. But milk formula contains 5 - $8 \mathrm{mg} / \mathrm{litre}$. Predominantly, breast fed babies of 12 - 23 months of age group have less of anaemia; $38.1 \%$ when compared to $59 \%$ of not predominantly breast fed babies. Iron absorption from breast milk is 2 - 3 times more efficient when compared to cow's milk. Of 12 - 23 years' age group who consumed milk and milk products have 47.72 of percentage of anaemia 
when compared $38.71 \%$ of not consuming milk and milk products. Similar observations were also made by Ziegler et al.

There was no significant relation seen between mother's education and employment with anaemia. In our study, $19.23 \%$ of mothers are school educated and rest have college education. Choi et al reported anaemia and iron deficiency anaemia among children of less educated mothers (10.8 vs $6.2 \%, \mathrm{p}=0.0324$ and 4.48 vs $1.78 \%, \mathrm{p}=0.0577$, respectively) than among children of more educated mothers. ${ }^{8}$

\section{CONCLUSION}

Prevalence of anaemia is high in children, in spite of various strategies like iron supplementation, food fortification and deworming. Prevalence is highest in children aged $6-11$ months. This cannot be prevented by gestational iron and folic acid supplementation. Timely introduction of complementary feeding is recommended to prevent anaemia. Adequate balanced diet is necessary to prevent obesity as well as malnutrition in children. Food habits showed significant association with anaemia in this study. Regular intake of cereals, pulse, vegetables and fruits is advised to prevent anaemia. Among the non-vegetarian group, regular intake of fish, meat and poultry and egg is recommended to decrease the prevalence of anaemia.

Thus, from this study we can conclude that timely introduction of complementary feeds and regular intake of fish, meat, poultry, egg, cereals, tubers, pulses, vegetables and fruits help in decreasing the prevalence of anaemia.

\section{REFERENCES}

[1] Benoist B, McLean E, Egli I, et al. Worldwide prevalence of Anaemia 1993-2005: WHO Global Database on Anaemia, WHO, Geneva, Switzerland, 2008.

[2] International Institute for Population Sciences and Macro International, National Family Health Survey (NFHS-3), 2005-06.

[3] Sales MC, de Queiroz E, Paiva de A. Association between anaemia and subclinical infection in children in Paraiba State, Brazil. Rev Bras Hematol E Hemoter 2011;33(2):96-9.

[4] Dos Santos RF, Gonzalez ES, de Albuquerque EC, et al. Prevalence of anaemia in under five-year-old children in a children's hospital in Recife, Brazil. Rev Bras Hematol E Hemoter 2011;33(2):100-4.

[5] George KA, Kumar NS, Lal JJ, et al. Anaemia and nutritional status of pre-school children in Kerala. Indian J Pediatr 2000;67(8):575-8.

[6] Osorio MM, Lira PI, Batista-Filho M, et al. Prevalence of anaemia in children 6-59 months old in the state of Pernambuco, Brazil. Rev Panam Salud Publica 2001;10(2):107-7.

[7] Awasthi S, Das R, Verma $T$, et al. Anaemia and undernutrition among preschool children in Uttar Pradesh, India. Indian Pediatr 2003;40(10):985-90.

[8] Choi HJ, Lee HJ, Jang HB, et al. Effects of maternal education on diet, anaemia, and iron deficiency in Korean school aged children. BMC Public Health 2011;11(1):870. 